Revista Eletrônica em Gestão, Educação e Tecnologia Ambiental Santa Maria, v. 20, n. 1, jan.-abr. 2016, p. 381-388

Revista do Centro de Ciências Naturais e Exatas - UFSM

ISSN : 22361170

\title{
Identificação das classes de metabólitos secundários no extrato etanólico dos frutos e folhas de Eugenia uniflora L.
}

\author{
Identification class of secondary metabolites in ethanolic extract of fruits and leaves \\ of Eugenia uniflora L.
}

\author{
Ana Cristina Oliveira da Silva ${ }^{1}$, Renato Abreu Lima ${ }^{2 *}$ \\ ${ }^{1}$ Discente do Curso de Ciências Biológicas, Faculdade São Lucas, Porto Velho-RO \\ ${ }^{2}$ Docente do Curso de Ciências Biológicas, Faculdade São Lucas, Porto Velho-RO
}

\begin{abstract}
Resumo
Este trabalho teve como objetivo realizar um estudo preliminar fitoquímico do extrato etanólico das folhas e frutos de E. uniflora. O presente trabalho consistiu na coleta vegetal na cidade de Porto Velho-RO, sendo as preparações dos extratos foram realizadas no Laboratório de Fitoquímica, sendo feito a limpeza, separação e pesagem do material ainda fresco, e levada para a estufa recirculação, por 48 a 72 horas a $50^{\circ} \mathrm{C}$. Em seguida, acrescentou-se 1 litro de etanol para as folhas e $350 \mathrm{~mL}$ de etanol para os frutos e deixado de repouso por sete dias. Posteriormente, o material foi submetido à destilação simples, e ao teste fitoquímico que consistiu na identificação de metabólitos secundários de acordo com a precipitação e coloração dos extratos diluídos em solução e reagentes específicos para cada teste de alcaloides, glicosídeos cardiotônicos, flavonoides, cumarinas, taninos, triterpenos e saponinas. Os testes fitoquímicos realizados no extrato etanólico das folhas e frutos de E. uniflora evidenciaram a presença de alcaloides, glicosídeos cardiotônicos, cumarinas, flavonoides e taninos. Porém, resultados negativos são saponinas e triterpenos. Conclui-se que o extrato etanólico das folhas e frutos de E. uniflora apresenta metabólitos secundários que precisam ser testados em ensaios biológicos in vitro e in vivo.
\end{abstract}

Palavras-chave: Pitanga, digestivo, medicinal.

\begin{abstract}
This study aimed to conduct a preliminary phytochemical study of the ethanol extract of the leaves and fruits of E. uniflora. This work consisted of the plant collection in Porto Velho, and the preparations of the extracts were performed at the Phytochemical Laboratory, being done cleaning, sorting and weighing of the still fresh material, and taken to the greenhouse recirculation, for 48 to 72 hours at $50^{\circ} \mathrm{C}$. Then she added 1 liter of ethanol for sheets and $350 \mathrm{~mL}$ of ethanol for fruit and left undisturbed for seven days. Subsequently, the material was subjected to simple distillation, and phytochemical test that consisted in the identification of secondary metabolites according to precipitation and coloration of extracts diluted in solution and specific reagents for each alkaloids test, cardiac glycosides, flavonoids, coumarins, tannins, triterpenes and saponins. Phytochemicals tests in ethanol extract of the leaves and fruits of E. uniflora showed the presence of alkaloids, cardiac glycosides, coumarins, flavonoids and tannins. However, negative results are saponins and triterpenes. It is concluded that the ethanol extract of the leaves and fruits of E. uniflora presents secondary metabolites that need to be tested in biological assays in vitro and in vivo.
\end{abstract}

Keywords: Pitanga, digestive, medicinal. 


\section{Introdução}

A utilização de plantas com fins medicinais, para tratamento, cura e prevenção de doenças, é uma das mais antigas formas de prática medicinal da humanidade. No início da década de 1990, a Organização Mundial de Saúde (OMS) divulgou que $65-80 \%$ da população dos países em desenvolvimento dependiam das plantas medicinais como única forma de acesso aos cuidados básicos de saúde (VEIGA-JÚNIOR et al., 2005).

A perda da biodiversidade original contribui para o afastamento das pessoas do contato com a flora e desta forma as plantas usadas com fins terapêuticos passam a ser cada vez mais restritas a ambientes antropizados. Portanto, resgatar este conhecimento e suas técnicas terapêuticas é uma maneira de deixar registrado um modo de aprendizado informal que contribui para a valorização da medicina popular, além de gerar informações sobre a saúde da comunidade local (PILLA et al., 2006).

A pitangueira (Eugenia uniflora L.) é uma espécie arbórea nativa do sul do Brasil, é largamente cultivada nas Américas, Ásia, África e Europa, por seus inúmeros cultivares. É uma espécie de ampla utilidade, é plantada por ser ornamental, frutífera e, também, por seus aspectos medicinais (BACKES; IRGANG, 2004; SOBRAL et al., 2006; HULLER; SCHOCK, 2011).

O chá das folhas é antirreumático, antidisentérico, febrífugo e utilizado contra diabetes. Os agricultores utilizam a pitanga também pela versatilidade dos frutos que, além de serem utilizados na cosmetologia, fornecem geleias, doces, refrescos, sorvetes, licores e vinhos todos de apreciável qualidade. A pitangueira é recomendada também para reflorestamentos heterogêneos destinados à recomposição de áreas degradadas de preservação permanente, visando a proporcionar alimento a avifauna (SILVANA et al., 2001).

O metabolismo dos vegetais é definido como o conjunto total das transformações das moléculas orgânicas, catalisadas por enzimas, que ocorre nas células vivas, suprindo o organismo de energia, renovando suas moléculas e garantindo a continuidade do estado organizado (MARZZOCO; TORRES, 2007; PEREIRA; CARDOSO, 2012), ocorrendo que plantas iguais possam ter metabólitos diferentes.

Os metabólitos secundários, geralmente de estrutura complexa, baixo peso molecular, possuem atividades biológicas marcantes e, diferentemente dos metabólitos primários, apresentam-se em baixas concentrações e em determinados grupos de plantas (BERG; LUBERT, 2008).

Diante das propriedades medicinais desta espécie, este trabalho teve como objetivo realizar um estudo preliminar fitoquímico das classes de metabólitos secundários do extrato etanólico das folhas e frutos de E. uniflora.

\section{Material e métodos}

As folhas e os frutos de E. uniflora foram coletados em um bairro da zona urbana no município de Porto Velho-RO com as coordenadas geográficas $8^{\circ} 49^{\prime} 34.19^{\prime}$ S. $063^{\circ} 55^{\prime} 59.87^{\prime \prime}$ W. Após a coleta, as folhas e frutos foram pesados separadamente ainda frescos e em seguida colocados, para desidratarem em estufa elétrica a $50^{\circ} \mathrm{C}$ por 72 horas. A partir das folhas e frutos devidamente secos, os mesmos foram triturados separadamente, e a partir do pó resultante, foi colocado em frascos e adicionado um volume de $1 \mathrm{~L}$ de etanol $95 \%$, nas folhas e $350 \mathrm{~mL}$ nos frutos por sete dias.

Posteriormente, os extratos foram filtrados e submetidos ao processo de rotaevaporação sob pressão reduzida. A realização do processo para identificar os metabólitos secundários do extrato bruto das folhas e frutos de E. uniflora foi realizada no Laboratório de Fitoquímica da Faculdade São Lucas, através do processo de rotaevaporação sob pressão reduzida. Foram realizados testes fitoquímicos com o extrato etanólico, baseados em precipitação e coloração dos extratos diluídos em solução e reativos específicos para cada teste conforme Radi; Terrones (2007):

\section{Alcaloides}

Para realizar o ensaio utilizou-se 2,0 mL da solução etanólica, sendo adicionados 2,0 $\mathrm{mL}$ de ácido clorídrico (10\%), onde aqueceu mistura por 10 minutos. Após o resfriamento, o extrato foi dividido em 
três tubos de ensaios e colocaram-se oito gotas, utilizando pipeta de Pasteur, dos seguintes reativos de reconhecimento:

Tubo 1 - Reativo de Mayer: observando formação de precipitado branco ou leve turvação branca;

Tubo 2 - Reativo de Dragendorff: observando formação de precipitado de coloração laranja a vermelho;

Tubo 3 - Reativo de Wagner: observando formação de precipitado de coloração alaranjado.

\section{Glicosídios Cardiotônicos}

A 2,0 mL de solução do extrato foram adicionados 3,0 mL de solução de acetato de chumbo a $10 \% \mathrm{e}$ 2,0 $\mathrm{mL}$ de água destilada. Aqueceu a mistura em banho-maria durante 10 minutos. Em seguida, o extrato foi filtrado e agitado com 10,0 mL de clorofórmio, separando a fase clorofórmica em quatro tubos de ensaio. Após a evaporação do clorofórmio, obteve-se a formação de resíduos nos tubos, os quais foram acrescidos dos seguintes reagentes:

Tubo 1: Realizou-se a reação de Salkowski para a determinação de núcleo esteroidal. A mudança da coloração amarela para roxo indica resultado positivo.

Tubo 2: 1,0 mL de Reativo de Kedde.

Coloração rosa ou azul-violeta ao visível indica cardenólidos, os bufadienólidos não reagem. A cor se atenua em poucos minutos.

Tubo 3: Realizou-se a reação de Keller-Kiliani (ácido acético glacial, numa gota de cloreto férrico III a $5 \%$ em metanol e ácido sulfúrico concentrado). Colorações intensas indica resultado positivo.

Tubo 4: Realizou-se a reação de Liebermann-Burchard.- Em 1,0 mL da amostra foram acrescentadas gotas de ácido acético acrescida de 3,0 mL anidrido acético/ácido sulfúrico (50:1, v/v). Resultado positivo: coloração verde, azul esverdeado, roxo a azul.

Tubo 5: Realizou-se a reação de Baljet. Em 1,0 mL da amostra, foram adicionadas oito gotas de ácido acético e 3,0 mL de clorofórmio. Resultado positivo: coloração laranja, roxo ou vermelho.

Tubo 6: Realizou-se a reação de Raymond (Filtraram-se o extrato e adicionaram-se 2 gotas de solução de cloreto férrico a $10 \%$ e duas gotas de acetato de chumbo a $10 \%)$. Resultado positivo: coloração amarela a roxo.

\section{Cumarinas}

Em um tubo de ensaio colocou-se 2,00 mL da solução etanólica, tampou-se com papel de filtro impregnado em solução $10 \%$ de $\mathrm{NaOH}$ e levou-se a banho de água a $100^{\circ} \mathrm{C}$ por alguns 10 minutos. Removeu-se o papel-filtro e examinou- se sob luz ultravioleta com $100 \mathrm{~nm}$ de comprimento de onda. A fluorescência amarela ou verde indica a presença de cumarinas.

\section{Flavonoides}

Esta pesquisa baseia-se na modificação da estrutura do flavonoide em presença de ácido. Colocouse em um tubo, 2,0 mL do extrato etanólico, sendo adicionado duas gotas de acetato de chumbo a 10\%. A presença de um precipitado corado indica positividades da reação.

\section{$\underline{\text { Taninos }}$}

A 2,00 mL do extrato etanólico, adicionou-se $10 \mathrm{~mL}$ de água destilada. Filtraram-se e adicionaram-se duas gotas, utilizando a pipeta de Pasteur, da solução de cloreto férrico a $10 \%$. Coloração azul indica possível presença de taninos hidrolisáveis, e coloração verde de taninos condensados.

\section{$\underline{\text { Saponinas }}$}

Neste ensaio, com 2,0 mL da solução etanólica, foi adicionado 5,0 $\mathrm{mL}$ de água destilada fervendo. Após resfriamento, agitou-se vigorosamente, deixando em repouso por 20 minutos. Classifica-se a presença de saponinas pela formação de espumas persistente. 


\section{Triterpenos}

Neste ensaio, com 2,0 mL da solução etanólica, foi adicionado 5,0 mL de clorofórmio. Após filtração, o extrato foi dividido em duas porções. Em cada um dos tubos realizaram-se as reações de Liebermann-Burchard e Salkowski. Os triterpenos desenvolvem coloração estável e os esteroides desenvolvem coloração mutável com o tempo.

\section{Resultados e discussão}

Para a identificação dos metabólitos secundários, foram obtidas por meio do protocolo experimental, desde a coleta até o extrato, as seguintes quantidades de extrato vegetal de E. uniflora (Tabela 1):

Tabela 1 - Demonstração do rendimento dos materiais vegetais do extrato etanólico das folhas e frutos de E. uniflora

\begin{tabular}{lccc}
\hline Material vegetal & Peso fresco $(\mathbf{k g})$ & Peso seco $(\mathbf{g})$ & $\begin{array}{c}\text { Rendimento do extrato } \\
(\mathbf{m L})\end{array}$ \\
Folhas & $1.068,65$ & 389,74 & 195 \\
Frutos & $1.117,41$ & 216,02 & 60 \\
\hline
\end{tabular}

Tabela 2 - Teste para reconhecimento de metabólitos secundários presente no extrato etanólico das folhas de E. uniflora

\begin{tabular}{lcc}
\hline Metabólitos secundários & Extrato etanólico & Coloração/Precipitação \\
Alcaloides & & \\
Reagente de Mayer & Negativo & Verde \\
Reagente de Wagner & Negativo & Verde \\
Reagente de Dragendorff & Positivo & Laranja \\
Glicosídeos Cardiotônicos & & \\
Reagente de Kedde & Negativo & Verde \\
Reagente de Keller-Killiani & Negativo & Verde escuro \\
Reagente de Lieberman & Positivo & Verde escuro \\
Reagente de Salkowski & Positivo & Amarelo \\
Reagente de Baljet & Positivo & Vermelho \\
Reagente de Raymond-Marthoud & Positivo & Roxo \\
Cumarinas & Negativo & Sem fluorescência \\
Flavonoides & Negativo & Verde \\
Taninos & Negativo & Verde \\
Hidrolisáveis & Positivo & Verde \\
Condensados & Negativo & Sem formação de espuma \\
Saponinas & Negativo & Verde \\
Triterpenos e/ou Esteroides & Positivo & Amarelo \\
Reagente Lierbermann-Buchard & & \\
Salkowski & & \\
& &
\end{tabular}

Para a identificação dos metabólitos secundários presentes no extrato etanólico das folhas, verificou-se a presença de alcaloides com reagente Dragendorff e negativos para os reagentes Mayer e Wagner. Para análise do teste de glicosídeos cardiotônicos verificou-se resultados positivos para os reagentes de Salkowski, Baljet, Raymond-Marthoud e Lieberman, enquanto que resultados negativos foram para Kedde e Keller-Killiani. Para a classe de metabólitos secundários cumarinas, observou-se a 
ausência de fluorescência, ou seja, notando-se resultado negativo. Para flavonoides revelou resultados negativos, enquanto que para saponinas não houve formação de espumas, resultando também em resultado negativo. Quanto à identificação das classes de triterpenos ou esteroides utilizando o reagente Lierbermann-Buchard verificou-se a ausência deste, porém utilizando o reagente de Salkowski o resultado foi positivo (Tabela 2).

Analisando a Tabela 3 pode-se observar resultados positivos que foram superiores ao extrato etanólico das folhas de E. uniflora. Para a identificação dos metabólitos secundários presentes no extrato etanólico dos frutos, verificou-se a presença de alcaloides com reagente Dragendorff e negativos para os reagentes Mayer e Wagner. Para análise do teste de glicosídeos cardiotônicos, notou-se resultados positivos para os reagentes de Salkowski, Baljet e Raymond-Marthoud, enquanto para Kedde, Keller-Killiani e Lieberman os resultados foram negativos. Com relação as cumarinas, observou-se a presença de fluorescência notando-se resultados positivos. Enquanto que para a classe de metabólitos secundários flavonoides revelaram resultados positivos. Por outro lado, resultados negativos foram para as saponinas, ou seja, não havendo formação de espumas. E por último, a classe de triterpenos ou esteroides utilizando o reagente Lierbermann-Buchard observou-se resultados negativos e para o reagente de Salkowski o resultado foi positivo.

Tabela 3 - Teste para reconhecimento de metabólitos secundários presente no extrato etanólico dos frutos de E. uniflora

Metabólitos secundários

\section{Alcaloides}

Reagente de Mayer

Reagente de Wagner

Reagente de Dragendorff

Glicosídeos Cardiotônicos

Reagente de Kedde

Reagente de Keller-Killiani

Reagente de Lieberman

Reagente de Salkowski

Reagente de Baljet

Reagente de Raymond-Marthoud

\section{Cumarinas}

Flavonoides

Taninos

Hidrolisáveis

Condensados

\section{Saponinas}

Triterpenos e/ou Esteroides

Reagente Lierbermann-Buchard Salkowski
Extrato etanólico

Negativo

Negativo

Positivo

Negativo

Negativo

Negativo

Positivo

Positivo

Positivo

Positivo

Positivo

Negativo

Positivo

Negativo

Negativo

Positivo
Coloração/Precipitação

Marrom

Marrom

Laranja

Amarelho

Verde escuro

Cinza

Amarelo

Vermelho

Roxo

Com fluorescência

Marrom

Verde

Verde

Sem formação de espumas

Verde

Amarelo

Os extratos de plantas contendo alcaloides, mais que no presente trabalho houve ausência nas folhas e frutos de E. uniflora, são utilizados como medicamentos, venenos e porções mágicas desde os primórdios da civilização. Desta maneira é difícil estabelecer a origem correta da descoberta destas substâncias. Registros indicam que o ópio era utilizado pelos Sumérios há 4000 anos a. C. devido as suas propriedades soporíficas e analgésicas (HOSTETTMAN et al., 2003). Porém, nota-se em alguns trabalhos científicos a ausência de alcaloides na família Myrtaceae, que é a mesma pertencente a da planta estudada neste trabalho.

Os flavonoides encontrados nos frutos e não nas folhas da E. uniflora representam um dos grupos fenólicos mais importantes e diversificados entre os produtos de origem natural. Essa classe de metabólitos secundários é amplamente distribuída no reino vegetal (SIMÕES et al., 2004). Eles 
participam de importantes funções no crescimento, desenvolvimento e na defesa dos vegetais contra o ataque de patógenos (DIXON; HARRISON, 1990).

Os taninos condensados encontrados nas folhas e frutos do extrato etanólico de E. uniflora ocorrem em uma ampla variedade de vegetais, podendo ser encontrados nas raízes, na casca, nas folhas, nos frutos, nas sementes e na seiva. São classificados em dois grupos: taninos hidrolisáveis e taninos condensados. Tanase é uma enzima extracelular, induzível, produzida na presença de ácido tânico por fungos, bactérias e leveduras (AGUILAR et al., 1999).

As classes de terpenos encontrados nas folhas e frutos de E. uniflora são de extrema relevância, pois os mesmos fazem composição importantes de óleos essenciais de diferentes espécies de Myrtaceae. A maioria deles contém de 10 a 30 átomos de carbono. Eles são derivados de uma unidade de cinco átomos de carbono isopreno. O limomeno, obtido do óleo do limão ou laranja, é um exemplo de terpeno (UCKO, 1992).

Os glicosídeos cardiotônicos encontrados nas folhas e frutos de E. uniflora são divididos em dois grupos, um com compostos de cadeia de vinte e três carbonos chamada cardenolídeos, e outro composto de cadeias de vinte e quatro carbonos chamados bufadienolídeos. Estes glicosídeos são usados na medicina para o tratamento da insuficiência cardíaca, e intoxicações, podem ocorrer depois do consumo de chás preparados por partes de plantas ou depois do consumo de flores, folhas ou sementes de plantas (VICKERY; VICKERY, 1981).

As cumarinas presentes nos frutos e não nas folhas de E. uniflora constituem uma classe de metabólitos secundários derivados do ácido cinâmico, encontrados em abundância no reino vegetal, nos fungos e bactérias. A esta classe de compostos atribuísse uma grande variedade de atividades biológicas, como a antimicrobiana, a antiviral, a anti-inflamatória, a antiespasmódica e antitumoral (MACHADO et al., 2001; LOGHKIN; SCKANYAN, 2006).

Com a identificação majoritária dos metabólitos secundários presentes no extrato etanólico dos frutos e não nas folhas de E. uniflora utilizando reagentes específicos, conclui-se que o mesmo apresenta compostos de grande interesse na medicina tradicional que precisam ser isolados, identificados e testados por meio de ensaios biológicos (WANG; SU, 2001).

Segundo Freitas et al. (2004) a produção de metabólitos secundários pela planta ocorre em função da interação planta versus ambiente em resposta a fatores químicos $(\mathrm{pH}$, temperatura e umidade) e biológicos (água, solo e fotossíntese). Este fato podem explicar resultados divergentes de extratos da mesma espécie, mas coletado em locais e períodos diferentes.

Os estímulos decorrentes do ambiente, no qual a planta se encontra podem redirecionar a rota metabólica, ocasionando a biossíntese de diferentes compostos. Dentre estes fatores, podem-se ressaltar as interações planta/microrganismos, planta/insetos e planta/planta; idade e estádio de desenvolvimento, fatores abióticos como luminosidade, temperatura, pluviosidade, nutrição, época e horário de coleta, bem como técnicas de colheita e pós-colheita. É válido ressaltar que estes fatores podem apresentar correlações entre si, não atuando isoladamente, podendo exercer influência conjunta no metabolismo secundário (MORAIS, 2009).

\section{Conclusão}

Com base nos resultados obtidos através do extrato etanólico das folhas e frutos de E. uniflora, conclui-se que a identificação fitoquímica realizada apresentou metabólitos secundários satisfatórios para a maioria dos reagentes testados apresentando alcaloides, glicosídeos cardiotônicos, taninos e triterpenos para o extrato etanólico das folhas, enquanto que para os frutos foram observados metabólitos secundários como alcaloides, glicosídeos cardiotônicos, cumarinas, taninos e triterpenos que são compostos de grande interesse na medicina tradicional.

No entanto, o metabólito secundário saponinas foi negativo para ambas as estruturas botânicas. No entanto, outras coletas precisam ser realizadas em diferentes períodos para que assim, se compare os metabólitos de diferentes estações do ano bem como, saber a quantidade de cada metabólito secundário. 


\section{Agradecimentos}

Ao Laboratório de Fitoquímica da Faculdade São Lucas pelo auxílio na produção dos extratos e a Universidade Federal de Rondônia pela destilação dos mesmos.

\section{Referências}

AGUILAR, C.; AUGUS, C.; GONZÁLEZ, G. V.; FAVELA, E. A comparison of methods to determine Tannin Acyl Hydrolase Activity. Braz. Archives Biologics Techonology, v. 42, n.3, p.355-361, 1999.

BACKES, P.; IRGANG, B. Mata Atlântica: as árvores e a paisagem. Porto Alegre: Paisagem do Sul, 396p. 2004

BERG, J.M.T.; LUBERT, J. Bioquímica. 6.ed. Rio de Janeiro: Guanabara Koogan, 545p. 2008.

DIXON, A. R.; HARRISON, M. J. Activation, structure, and organization of genes involved in microbial defense in plants. Advent Genetics, v.28, n.2, p.165-234, 1990.

FREITAS, M.S.M.; SOUZA, P.H.; BELLO, O.I.; JAQUES, R.S. Crescimento e produção de fenóis totais em carqueja [Baccharis trimera (Less.) D.C.] em resposta à inoculação com fungos micorrízicos arbusculares, na presença e na ausência de adubação mineral. Revista Brasileira de Plantas Medicinais, v.6, n.3, p.30-34, 2004.

HOSTETTMAN, K.; QUEIROZ, E.F.; VIEIRA, P.C. Princípios ativos de plantas superiores. São Carlos: EdUFSCar, 2003.

HULLER, A.; SCHOCHK, A.A. Avaliação do potencial alelopático de três espécies de Eugenia L. (Myrtaceae) sobre o processo germinativo de Lactuca sativa L. Revista de Ciências Ambientais, v.5, n.1, p.25-37, 2011.

LOGHKIN, A.V.; SCKANYAN, E.I. Natural coumarin: methods of isolation and analysis. Pharmacology Chemical, v.40, n.2, p.337-346, 2006.

MACHADO, A.E.H.; MIRANDA, J.A.; SEVERINO, D.E.; OLIVEIRA, A.M.F.P. Photophysical properties of two new psoralen analogues. Journal of Photochemical Photobiology, v.14, n.6, p.7276, 2001.

MARZZOCO, A.; TORRES, B.B. Bioquímica Básica. 3.ed. Rio de Janeiro: Guanabara Koogan, 2007. 736p.

MORAIS, L.A.S. Influência dos fatores abióticos na composição química dos óleos essenciais. Horticultura Brasileira, v.27, n.2, (Suplemento - CD Rom), agosto 2009.

PEREIRA, R.J.; CARDOSO, M.G. Metabólitos secundários vegetais e benefícios antioxidantes. Journal of Biotechnology, v.3, n.4, p.146-152, 2012.

PILLA, M.A.C.; AMOROZO, M.C.M.; FURLAN, A. Obtenção e uso das plantas medicinais no distrito de Martim Francisco, Município de Mogi-Mirim, SP. Acta Botânica Brasílica, v.20, n.4, p.789-802, 2006. 
RADI, P.A.; TERRONES, M.G.H. Metabólitos secundários de plantas medicinais. Revista Brasileira de Farmácia, v.20, n.2, p18-22, 2007.

SILVANA, D.E.P.; SCALON, Q.; FILHO, H.S.; MARILÚCIA, R.; RIGONI, F.V. Germinação e crescimento de mudas de pitangueira (Eugenia uniflora L.) sob condições de sombreamento. Revista Brasileira de Fruticultura, v.23, n.3, p.652-655, 2001.

SIMÕES, C.M.O.; SCHENKEL, E.P.; GOSMANN, G.; MELLO, J.C.P.; MENTZ, L.A.; PETROVICK, P.R. Farmacognosia: da Planta ao Medicamento. 5.ed. Editora da UFSC: Santa Catarina, 2004.

SOBRAL, M. JARENKOW, J.A.; BRACK, P.; IRGANG, B.; LAROCCA, J.; RODRIGUES, R.S. Flora arbórea e arborescente do Rio Grande do Sul, Brasil. São Carlos: RiMa/Novo Ambiente, 350p. 2006.

UCKO, D.A. Química para as ciências da saúde: uma introdução à Química Geral, orgânica e Biológica. São Paulo, 1992.

VEIGA-JÚNIOR, V.F.; PINTO, A.C.; MACIEL, M.A.; MACIEL, M. Plantas medicinais: cura segura? Química Nova, v.28, n.3, p.519-528, 2005.

VICKERY, M. L.; VICKERY, B. Secondary plant metabolism. Hong Kong: The Macmillan Press Ltda, 1981.

WANG, M. Y.; SU, C. Cancer preventive effect of Morinda citrifolia (noni). Annals of the New York Academic Sciences, v.9, n.2, p.161-168, 2001. 